\title{
Association of sleep duration with stroke, myocardial infarction, and tumors in a Chinese population with metabolic syndrome: a retrospective study
}

Yingnan YE ${ }^{1,2}$, Linxi ZHANG ${ }^{1}$, Anping WANG ${ }^{1}$, Yuxia Wang ${ }^{1,2}$, Shiqing WANG ${ }^{1,2}$, Guang NING ${ }^{3}$ and Yiming $\mathrm{MU}^{1,2^{*}}$

\begin{abstract}
Background: Previous studies have suggested that abnormal sleep duration is associated with increased risk of metabolic syndrome (MetS). However, evidence on the association of sleep duration with stroke, myocardial infarction (MI) and tumors in populations with MetS is limited.

Methods: A total of 8968 participants (2754 with MetS at baseline) were recruited in this retrospective study between March 2012 and December 2012. The baseline characteristics and information on sleep duration were collected by self-reported questionnaires. In addition, physical examination and blood test were also performed. The outcome events in this study were new onset of stroke, $\mathrm{Ml}$ and tumors during subsequent follow-up. Multivariate logistic regressions were adopted to investigate the relationships between sleep duration and outcome events among different sleep duration groups ( $<6 \mathrm{~h}, 6-7 \mathrm{~h}, 7-8 \mathrm{~h}$ [reference], $8-9 \mathrm{~h}$, and $>9 \mathrm{~h}$ per day) in participants with MetS.

Results: The mean self-reported total sleep duration was $7.8 \pm 1.2 \mathrm{~h}$. Compared with participants with MetS slept for 7-8 $\mathrm{h}$ per day, the adjusted odds ratios (ORs) for those slept for $>9 \mathrm{~h}$ in stroke, $\mathrm{Ml}$ and tumors were 2.014 (95\% confidence interval [Cl]: 1.184-3.426, $P=0.010), 1.731$ (95\% Cl: 0.896-3.344, $P=0.102$ ) and 2.159 (95\% Cl: 0.991-4.704, $P=0.053)$, respectively, whereas the adjusted ORs for those slept for $<6 \mathrm{~h}$ in stroke, $\mathrm{Ml}$ and tumors were $2.249(95 \%$ $\mathrm{Cl}: 0.973-5.195, P=0.058), 1.213(95 \% \mathrm{Cl}, 0.358-4.104, P=0.756)$ and $1.743(95 \% \mathrm{Cl}, 0.396-7.668, P=0.462)$, respectively.
\end{abstract}

Conclusions: Long sleep duration ( $>9 \mathrm{~h}$ ) significantly increased the risk of stroke but not $\mathrm{Ml}$ and tumors in individuals with MetS compared with $7-8 \mathrm{~h}$ of sleep duration. Short sleep duration $(<6 \mathrm{~h})$ was not associated with the increased risk of stroke, Ml and tumors in individuals with MetS.

Keywords: Sleep duration, Metabolic syndrome, Stroke, Myocardial infarction, Tumors, Cohort, Chinese population

\footnotetext{
* Correspondence: znmf89898@sohu.com

'Department of Endocrinology, Chest Hospital Affiliated to Nankai University, School of Medicine, Nankai University, Tianjin 300071, China

${ }^{2}$ Department of Endocrinology, Chinese PLA General Hospital, Medical

School of Chinese PLA, No.28, Fuxing Road, Haidian District, Beijing 100853, China

Full list of author information is available at the end of the article
}

\section{Introduction}

Metabolic syndrome (MetS) is a well-defined risk factor for cardiovascular disease (CVD) [1] and mortality [2]. Recently, sleep has been recognized as a modifiable contributor to MetS. Previous studies have reported a potential association between sleep duration and the development of MetS [3, 4], as well as each of its

(c) The Author(s). 2020 Open Access This article is licensed under a Creative Commons Attribution 4.0 International License, which permits use, sharing, adaptation, distribution and reproduction in any medium or format, as long as you give appropriate credit to the original author(s) and the source, provide a link to the Creative Commons licence, and indicate if changes were made. The images or other third party material in this article are included in the article's Creative Commons licence, unless indicated otherwise in a credit line to the material. If material is not included in the article's Creative Commons licence and your intended use is not permitted by statutory regulation or exceeds the permitted use, you will need to obtain permission directly from the copyright holder. To view a copy of this licence, visit http://creativecommons.org/licenses/by/4.0/ The Creative Commons Public Domain Dedication waiver (http://creativecommons.org/publicdomain/zero/1.0/) applies to the data made available in this article, unless otherwise stated in a credit line to the data. 
components, (i.e. diabetes [5], obesity [6], hypertension [7] and dyslipidemia [8]). Moreover, sleep duration was also found to be associated with CVD [9], stroke [10] and mortality [11].

Currently, evidence on the relationship of sleep duration with CVD and tumors in patients with MetS was still limited. A US study enrolled 1344 participants with MetS found that $<6 \mathrm{~h}$ sleep duration increased the risk of mortality caused by CVD and cerebrovascular diseases [12]. However, given a U-shape relationship usually existed in published epidemiological studies [13, 14], the effect of sleep duration as continuous type on varying health outcomes should be assessed. Hence it is hypothesized that long sleep duration ( $>9 \mathrm{~h}$ per day) and short sleep duration $(<6 \mathrm{~h}$ per day) might increase the risk of stroke, myocardial infarction (MI) and tumors in individuals with MetS, compared with those slept for 7-8 h per day. Therefore, the current study was conducted to assess the association of sleep duration with stroke, MI, and tumors in a Chinese population with MetS.

\section{Methods}

Participants and public involvement

All participants have given written informed consent for authorizing to use their data. The study protocol was approved by the Committee on Human Research at Rui-Jin Hospital, School of Medicine, Shanghai Jiao Tong University (2014 clinical trial ethics approval No. 52).

\section{Study design}

The participants in this retrospective study were from an ongoing longitudinal study (Risk Evaluation of cAncers in Chinese diabeTic Individuals, REACTION) that was designed to investigate the relationship between type 2 diabetes, prediabetes and the risk of cancer in Chinese population [15]. All permanent residents aged 35-75 year-old of the Jingding, Laoshan and Gucheng communities in Beijing, China were invited to participate by the primary health care centers. All the included participants lived in developed urban area and represent general middle-aged and elderly population of Beijing. A total of 19,314 persons were recruited between March 2012 and December 2012. Among them, 10,216 participants were followed up in 2015. In the current study, participants were additionally excluded as following: 1 ) self-reported sleep duration $(<4 \mathrm{~h}$ or $>12 \mathrm{~h})$ due to too few participants; 2) indefinite diagnosis of MetS, stroke, MI, and tumors; and 3) substantial missing data.

Sample size calculations (PASS 11.0) were done based on a twosided type I error of $5 \%$ and a power of $80 \%$. Assuming an incidence of stroke was 3.5\% in participants with MetS and the odds ratio (OR) for $>9 \mathrm{~h}$ of sleep duration versus 7-8 h was 1.5, 2052 participants would be required to identify the difference between the two groups. To compensate for losses to follow-up and to be powered for the primary endpoint assessment, the enrolment of a total of 2300 participants was planned.

\section{Questionnaire and data collection}

Standardized questionnaires were used to collect baseline information, including self-reported sleep duration, medical history, physical exercise, depressive symptoms, smoking, and alcohol consumption. Total sleep duration of each individual was calculated from the time of sleeping to the time of waking-up. Participants were divided into five groups $(<6,6-7 \mathrm{~h}, 7-8 \mathrm{~h}, 8-9 \mathrm{~h}$, and $>9 \mathrm{~h}$ per day) based on their sleep duration, and $7-8 \mathrm{~h}$ of sleep duration was generally considered as the most appropriate sleep duration [16]. Depression symptoms were assessed using the Patient Health Questionnaire-9 (PHQ-9), which has been described in detail elsewhere [17]. Physical activity was defined as engaging in various sports more than once a week or engaging in heavy physical labor, such as steelmaking, agriculture, and casting. Smokers and drinkers were defined as participants who smoked one or more cigarettes per day and drank alcohol once or more a week for at least 6 months, respectively.

The height, weight, waist circumference and hip circumference for each participant were measured using anthropometric measurements. Body mass index (BMI) was calculated as body weight in kilograms divided by body height in meters squared $\left(\mathrm{kg} / \mathrm{m}^{2}\right)$. Blood pressure was measured three times at one-minute intervals using an Ohm electronic sphygmomanometer after seating for relax at least $5 \mathrm{~min}$, and the average of three measurements was used for analysis.

\section{Blood test}

Fasting blood samples were collected in the morning, and the level of triglycerides (TGs), total cholesterol (TC), low-density lipoprotein (LDL), high-density lipoprotein (HDL), fasting blood glucose (FBG), and postprandial blood glucose (PBG) were measured using an autoanalyser (Cobas 8000 modular analyzer series, Roche Diagnostics, Basel, Switzer land) (A.P.W and Y.X.W). Glycosylated hemoglobin A1c (HbA1c) was determined by high performance liquid chromatography using the VARIANT II Hemoglobin Testing System (Tosoh Corporation, Tokyo, Japan). Fasting and postprandial blood insulin levels were measured using the glucose oxidase-peroxidase method. Participants without a history of diabetes mellitus (DM) underwent a 75-g oral glucose tolerance test, while those with DM underwent a 100 -g oral steam bread tolerance test.

\section{Metabolic syndrome}

MetS was defined as having any 3 of the following 4 conditions according to the "Recommendations on metabolic 
syndrome from the Chinese Diabetes Association" [18]: 1) Overweight or obesity (BMI $\left.>25 \mathrm{~kg} / \mathrm{m}^{2}\right)$; 2) abnormal glucose metabolism (FBG $\geq 6.1 \mathrm{mmol} / \mathrm{L}$ or $\mathrm{PBG} \geq 7.8 \mathrm{mmol} / \mathrm{L}$ ); 3) hypertension (systolic blood pressure $[\mathrm{SBP}] \geq 140 \mathrm{mmHg}$ and/or diastolic blood pressure $[\mathrm{DBP}] \geq 90 \mathrm{mmHg}$, or a definite medical history of hypertension); and 4) abnormal lipid metabolism (TGs $\geq 1.7 \mathrm{mmol} / \mathrm{L}$ or $\mathrm{HDL}<0.9 \mathrm{mmol} / \mathrm{L}$ (for males) $/<1.0 \mathrm{mmol} / \mathrm{L}$ (for females)).

\section{Outcomes}

The outcome in the study were new onset stroke, MI and tumors during subsequent follow-up. The follow-up was performed via face to face visit or telephone visit. Participants were required to report the absence or presence of outcome events, and to provide information about the date of onset, whether and where they were hospitalized, clinical manifestations at the time of onset, and any clinical examination they underwent. The investigators (Y.N.Y and L.X.Z) would then go to these hospitals to review their medical records to ensure that data were correct.

\section{Statistical analysis}

Continuous variables are presented as mean with standard deviation (SD) for those with normal distribution, and median with interquartile range (IQR, 25th - 75th) for those with skewed distributions. Categorical data are presented as count with proportions. One-way analysis of variance (ANOVA) and chi-square test were used as appropriate to test the differences in the general characteristics. Multivariate logistic regression was used to calculate the ORs for various outcome events in different sleep duration groups $(<6 \mathrm{~h}, 6-7 \mathrm{~h}, 7-8 \mathrm{~h}$ [reference], 8$9 \mathrm{~h}$, and $>9 \mathrm{~h}$ ). Three models were developed: Model 1 was not adjusted any covariates; Model 2 adjusted for age, sex and BMI; Model 3 adjusted for covariates in model 2 plus SBP, waist circumference, hip circumference, depression, blood glucose, triglycerides and physical activity. Statistical analysis was performed using SPSS software version 19.0 (Chicago, IL, USA). A twosided $P<0.5$ were considered statistically significance.

\section{Results}

\section{Participant characteristics}

A total of 8968 participants (3111 males and 5857 females), with a mean age of $56.7 \pm 7.7$ years old, were included in the study between March and December 2012 (Table 1 and Supplementary Fig. S1). The mean selfreported total sleep duration was $7.8 \pm 1.2 \mathrm{~h}$ per day. The prevalence of overweight/obesity, hypertension, abnormal glucose metabolism and abnormal lipid metabolism were 57.0, 44.8, 47.0, and 33.2\%, respectively. In all participants, those who slept for $<7 \mathrm{~h}$ or $>8 \mathrm{~h}$ per day were more likely to be overweight and depressive, and to have hypertension, abnormal glucose metabolism, abnormal lipid metabolism and MetS than those slept for 7-8 h per day. Significant differences were also observed between different sleep duration groups in age, BMI, waist circumference, hip circumference and TGs. The prevalence of stroke, MI and tumors at baseline was similar among different sleep duration groups.

MetS at baseline was observed in 2752 (30.7\%) participants. In participant with MetS, there were no significant differences between different sleep duration groups in blood glucose, blood lipid and BMI (Table 2). Only hypertension, one component of MetS, was significantly associated with sleep duration. Additionally, there were significant differences between different sleep duration groups in age, alcohol consumption, hip circumference, and depression among these sleep duration groups.

\section{The association between sleep duration and MetS}

At baseline, compared to participants who slept for 7-8 $\mathrm{h}$ per day, the ORs for MetS in those who slept for $<6 \mathrm{~h}$, 6-7 h, 8-9 h and $>9 \mathrm{~h}$ were 1.145 (95\% confidence interval $[\mathrm{CI}]: 0.883-1.485, P=0.308), 1.070$ (95\% CI: $0.919-$ 1.247, $P=0.381$ ), 1.210 (95\% CI: $1.084-1.352, P=0.001$ ) and 1.564 (95\% CI: $1.342-1.821, P<0.001)$, respectively. After adjusting for age, sex, SBP, BMI, depression, blood glucose, TGs and physical activity, the ORs for MetS of individuals who slept for $<6 \mathrm{~h}, 6-7 \mathrm{~h}, 8-9 \mathrm{~h}$ and $>9 \mathrm{~h}$ were 1.034 (95\% CI: $0.711-1.505, P=0.861), 1.027$ (95\% CI: $0.824-1.281, P=0.810$ ), 1.125 (95\% CI: $0.960-1.319$, $P=0.145)$ and 1.218 (95\% CI: $0.969-1.531, P=0.091)$, respectively (Fig. 1).

At follow-up, 1033 new onset MetS were observed. Compared with individuals who slept for 7-8 h per day, the risk of new onset MetS did not differ significantly for those who slept for $<6 \mathrm{~h}$ (OR: 1.251; 95\% CI: $0.752-$ 2.078; $P=0.388$ ), 6-7 h (OR: 0.761; 95\% CI: 0.563-1.030; $P=0.077$ ), 8-9 h (OR: 0.897; 95\% CI: 0.724-1.111; $P=$ 0.318 ), and $>9$ h (OR: $0.957 ; 95 \%$ CI: $0.690-1.327 ; P=$ 0.793), respectively (Fig. 1).

\section{The association between sleep duration and outcome events} During follow-up, 267 of stroke, 162 of MI and 159 of tumors were identified, respectively. In participants with baseline MetS, the number of events was 114 in stroke, 81 in MI and 49 in tumors (Fig. 2). Compared with participants with MetS slept for 7-8 h per day, the adjusted ORs for those slept for $>9 \mathrm{~h}$ in stroke, MI and tumors were 2.014 (95\% CI: 1.184-3.426, $P=0.010), 1.731$ (95\% CI: $0.896-3.344, P=0.102)$ and 2.159 (95\% CI: $0.991-$ $4.704, P=0.053$ ), respectively (Table 3 ), whereas the adjusted ORs for those slept $<6 \mathrm{~h}$ for stroke, MI and tumors were 2.249 (95\% CI: 0.973-5.195, $P=0.058$ ), 1.213 (95\% CI: $0.358-4.104, P=0.756$ ) and 1.743 (95\% CI: $0.396-7.668, P=0.462$ ), respectively (Table 3 ). Moreover, the incidence of stroke had a near U-shape curve 
Table 1 Baseline information according to self-reported total sleep duration among general participants

\begin{tabular}{|c|c|c|c|c|c|c|c|}
\hline & $\operatorname{ALL}(n=8968)$ & Sleep duration ( & & & & & $P$ value \\
\hline & & $<6(n=280)$ & $6-7(n=950)$ & $7-8(n=4785)$ & $8-9(n=2114)$ & $>9(n=839)$ & \\
\hline Age, years & $56.7 \pm 7.7$ & $57.5 \pm 7.4$ & $56.4 \pm 7.2$ & $57.5 \pm 8.8$ & $57.3 \pm 8.1$ & $58.1 \pm 8.6$ & $<0.001$ \\
\hline Male, \% & 34.7 (3111) & $35.0(98)$ & $31.9(303)$ & $34.4(1648)$ & $35.8(756)$ & $36.5(306)$ & 0.225 \\
\hline Waist circumference, cm & $83.8 \pm 8.9$ & $84.9 \pm 9.4$ & $84.4 \pm 9.2$ & $86.0 \pm 9.9$ & $83.6 \pm 8.7$ & $84.1 \pm 9.1$ & 0.006 \\
\hline Hip circumference, cm & $94.4 \pm 6.9$ & $95.4 \pm 7.2$ & $95.2 \pm 7.0$ & $97.0 \pm 7.8$ & $94.0 \pm 6.7$ & $93.8 \pm 7.1$ & $<0.001$ \\
\hline $\mathrm{BMl}, \mathrm{kg} / \mathrm{m} 2$ & $25.7 \pm 3.4$ & $26.0 \pm 3.3$ & $26.0 \pm 3.5$ & $24.7 \pm 3.7$ & $25.7 \pm 3.4$ & $25.8 \pm 3.6$ & 0.032 \\
\hline Stroke history, \% & $2.8(250)$ & $4.3(12)$ & $3.4(32)$ & $2.4(113)$ & $2.9(62)$ & $3.7(31)$ & 0.051 \\
\hline Myocardial infarction history, \% & $1.1(102)$ & $1.4(4)$ & $1.2(11)$ & $0.9(42)$ & $1.4(30)$ & $1.8(15)$ & 0.102 \\
\hline Tumor history, \% & $2.0(183)$ & $1.8(5)$ & $2.0(19)$ & $1.9(89)$ & $2.4(50)$ & $2.4(20)$ & 0.647 \\
\hline Smoking habits & & & & & & & 0.606 \\
\hline Regular smoker, \% & $16.2(1449)$ & $16.4(46)$ & $16.6(158)$ & $16.2(777)$ & $15.6(330)$ & $16.4(138)$ & \\
\hline Sometimes smoker, \% & $2.2(197)$ & $3.6(10)$ & $2.5(24)$ & $2.3(110)$ & $1.8(39)$ & $1.7(14)$ & \\
\hline Never smoker, \% & $81.6(7322)$ & $80.0(224)$ & $80.8(768)$ & $81.5(3898)$ & $82.5(1745)$ & $81.9(687)$ & \\
\hline Drinking habits & & & & & & & 0.297 \\
\hline Regular drinker, \% & $10.2(916)$ & $11.1(31)$ & $11.6(110)$ & $9.7(466)$ & $10.1(214)$ & $11.3(95)$ & \\
\hline Sometimes drinker, \% & 18.9 (1698) & $20.7(58)$ & $17.8(169)$ & $19.7(945)$ & $17.9(379)$ & $17.5(147)$ & \\
\hline Never drinker, \% & 70.9 (6354) & $68.2(191)$ & $70.6(671)$ & 70.5 (3374) & $71.9(1521)$ & $71.2(597)$ & \\
\hline Depression symptoms & & & & & & & $<0.001$ \\
\hline Mild depression, \% & $5.6(504)$ & $12.1(34)$ & $7.6(72)$ & 4.9 (233) & $5.2(110)$ & $6.6(55)$ & \\
\hline $\begin{array}{l}\text { Moderate or severe depression, } \\
\%\end{array}$ & $1.1(97)$ & $3.9(11)$ & $1.1(10)$ & $0.9(42)$ & $0.9(18)$ & $1.9(16)$ & \\
\hline Physical activity, \% & $9.8(875)$ & $10.7(30)$ & $8.8(84)$ & $10.2(488)$ & 9.1 (193) & $9.5(80)$ & 0.518 \\
\hline Abnormal glucose metabolism, \% & $47.0(4217)$ & $47.1(132)$ & $46.1(438)$ & 44.9 (2149) & $49.4(1045)$ & $54.0(453)$ & $<0.001$ \\
\hline Overweight (BMI $\geq 25), \%$ & $57.0(5108)$ & $65.0(182)$ & $58.6(557)$ & $55.8(2672)$ & $56.1(1186)$ & $60.9(511)$ & 0.002 \\
\hline Hypertension, \% & 44.8 (4019) & $43.6(122)$ & $43.7(415)$ & $42.4(2029)$ & $48.5(1026)$ & $50.9(427)$ & $<0.001$ \\
\hline Abnormal lipid metabolism, \% & $33.2(2974)$ & $30.0(84)$ & $31.5(299)$ & $32.3(1546)$ & $34.0(719)$ & $38.9(326)$ & 0.002 \\
\hline Metabolic syndrome, \% & 30.7 (2754) & $31.4(88)$ & $30.0(285)$ & $28.6(1368)$ & $32.6(690)$ & $38.5(323)$ & $<0.001$ \\
\hline $\mathrm{HbA} 1 \mathrm{c}, \%$ & $5.8(5.5,6.3)$ & $5.9(5.5,6.3)$ & $5.9(5.6,6.4)$ & $5.8(5.5,6.3)$ & $5.9(5.5,6.3)$ & $5.9(5.5,6.4)$ & 0.002 \\
\hline $\mathrm{SBP}, \mathrm{mmHg}$ & $131.9 \pm 17.7$ & $131.6 \pm 16.8$ & $131.1 \pm 15.8$ & $131.9 \pm 20.3$ & $133.0 \pm 18.8$ & $133.9 \pm 18.8$ & $<0.001$ \\
\hline $\mathrm{DBP}, \mathrm{mmHh}$ & $75.9 \pm 12.9$ & $74.9 \pm 8.9$ & $75.6 \pm 9.7$ & $77.6 \pm 10.9$ & $76.2 \pm 15.0$ & $75.7 \pm 10.1$ & 0.452 \\
\hline TGs, mmol/L & $1.33(0.97,1.87)$ & $1.27(0.97,1.82)$ & $1.28(0.96,1.83)$ & $1.33(0.97,1.88)$ & $1.36(0.96,1.90)$ & $1.36(0.99,1.88)$ & 0.006 \\
\hline $\mathrm{TC}, \mathrm{mmol} / \mathrm{L}$ & $5.23 \pm 1.00$ & $5.19 \pm 0.89$ & $5.24 \pm 0.98$ & $5.12 \pm 1.13$ & $5.21 \pm 0.95$ & $5.27 \pm 1.05$ & 0.585 \\
\hline $\mathrm{HDL}, \mathrm{mmol} / \mathrm{L}$ & $1.44 \pm 1.63$ & $1.44 \pm 0.38$ & $1.44 \pm 0.37$ & $1.33 \pm 0.34$ & $1.40 \pm 0.35$ & $1.40 \pm 0.34$ & 0.555 \\
\hline $\mathrm{LDL}, \mathrm{mmol} / \mathrm{L}$ & $3.20 \pm 0.81$ & $3.14 \pm 0.76$ & $3.20 \pm 0.81$ & $3.02 \pm 0.89$ & $3.20 \pm 0.78$ & $3.23 \pm 0.87$ & 0.493 \\
\hline $\mathrm{FBG}, \mathrm{mmol} / \mathrm{L}$ & $5.32(4.93,6.03)$ & $5.32(4.93,6.00)$ & $5.32(4.92,6.05)$ & $5.28(4.91,5.96)$ & $5.37(4.94,6.10)$ & $5.41(5.01,6.27)$ & 0.001 \\
\hline $\mathrm{PBG}, \mathrm{mmol} / \mathrm{L}$ & $\begin{array}{l}7.98(6.46 \\
10.66)\end{array}$ & $\begin{array}{l}8.18(6.42 \\
10.93)\end{array}$ & $\begin{array}{l}7.89(6.46 \\
10.51)\end{array}$ & $\begin{array}{l}7.92(6.45 \\
10.50)\end{array}$ & $\begin{array}{l}8.15(6.49 \\
11.03)\end{array}$ & $\begin{array}{l}8.20(6.51 \\
10.96)\end{array}$ & $<0.001$ \\
\hline
\end{tabular}

Data were presented \% (n), mean (standard deviation), or median (25-75 percentile)

Abbreviation: BMI Body mass index; HbA1c Glycosylated hemoglobin A1c; SBP Systolic blood pressure; DBP Diastolic blood pressure; TGs Triglycerides; TC Total cholesterol; HDL High density lipoprotein; LDL Low density lipoprotein; FBG Fasting blood glucose; PBG Postprandial blood glucose

relationship with sleep duration (Fig. 2). For participants without MetS, the risks of stroke, MI and tumors were not significantly different between the different sleep duration groups.

\section{Discussion}

The present study investigated the associations between sleep duration and the occurrence of stroke, MI and tumors in a Chinese population with MetS. The findings suggested that compared to participants who slept for $7-8 \mathrm{~h}$ per day, those slept for $>9 \mathrm{~h}$ had a significantly 
Table 2 Baseline information according to self-reported total sleep duration among participants with metabolic syndrome

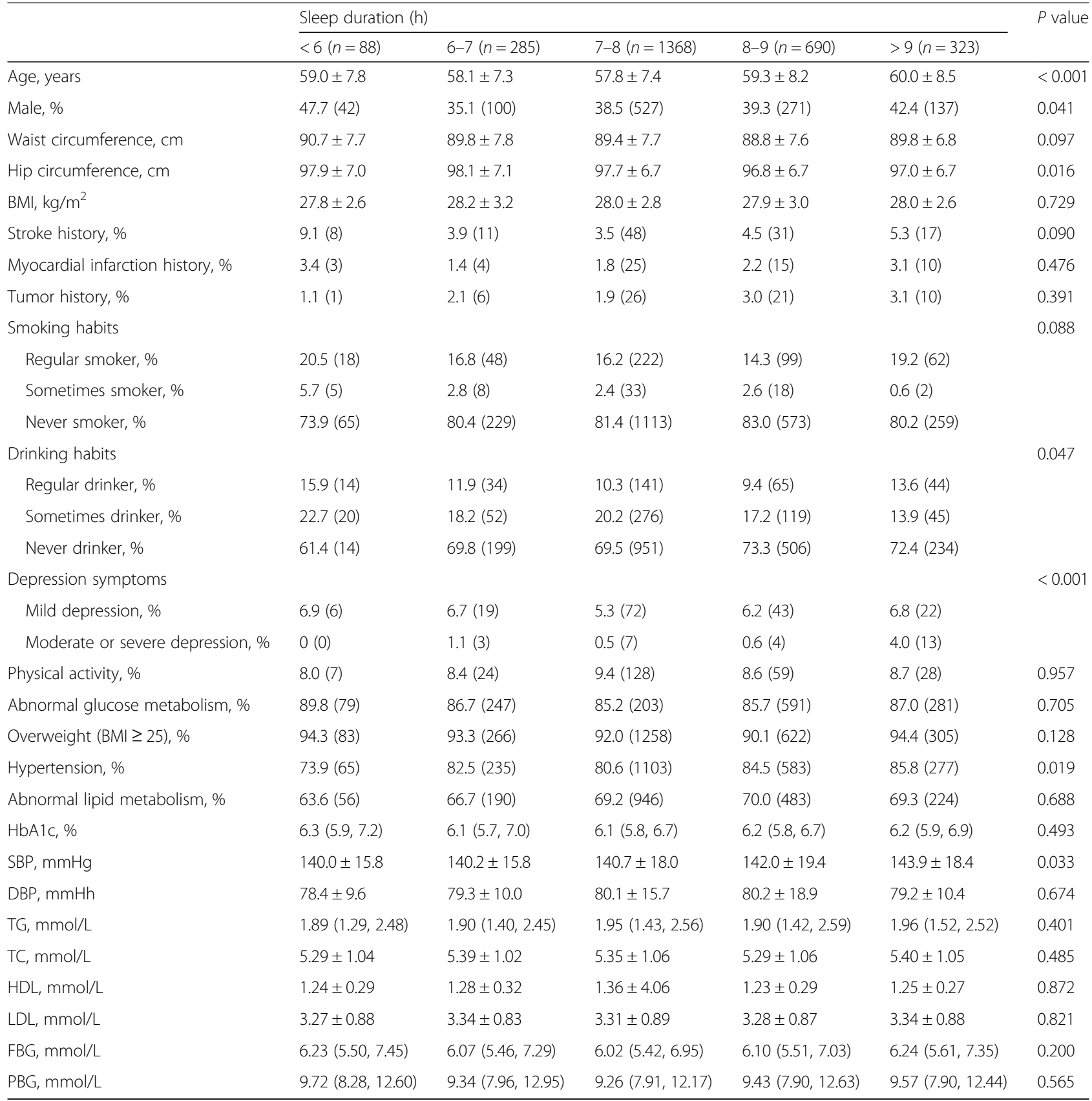

Data were presented $\%(n)$, mean (standard deviation), or median (25-75 percentile)

Abbreviation: BMI Body mass index; HbA1c Glycosylated hemoglobin A1c; SBP Systolic blood pressure; DBP Diastolic blood pressure; TGs Triglycerides; TC Total cholesterol; HDL High density lipoprotein; LDL Low density lipoprotein; FBG Fasting blood glucose; PBG Postprandial blood glucose

increased risk of stroke but a similar risk of $\mathrm{MI}$ and tumors, while those slept for $<6 \mathrm{~h}$ had a similar risk of stroke, MI and tumors.

The current study investigated the associations between sleep duration and stroke, MI and tumors, which are closely related to the survival, health status and quality of life of population. Previous study [12] had reported that $<6 \mathrm{~h}$ of sleep duration increased the risk of MetS related mortality. The current study added evidence that
$>9 \mathrm{~h}$ of sleep duration was also associated with adverse events in MetS patients. However, significant association was only identified between $>9 \mathrm{~h}$ of sleep duration and stroke, other results just showed a trend towards association but did not reach statistical significance. The results were possibly ascribed to that not only the limited sample size but also the small numbers of subjects with outcome events. A second follow-up of these participants is currently underway, and the findings will be updated and 


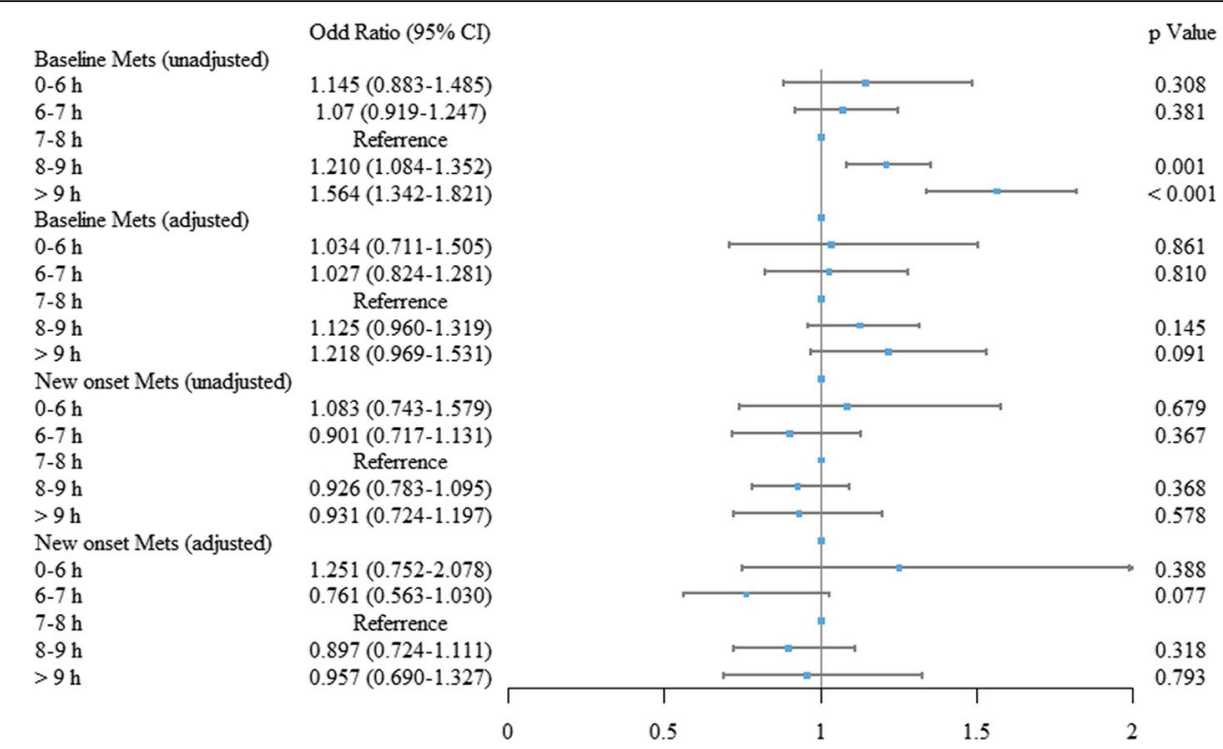

Fig. 1 The relationship between sleep duration and metabolic syndrome. The forest plot summarised the ORs (95\% Cl) of different sleep durations for baseline or new onset metabolic syndrome

further validated in future studies. Even though, these findings also suggest that sleep management might play an important role in patients with MetS.

The association between sleep and the prognosis of MetS might be partially explained as following. First, participants with worse sleep habits could also have higher cardiovascular risk, indicated by higher prevalence of obesity, depression, hypertension, abnormal glucose metabolism, and abnormal lipid metabolism. Second, inadequate sleep durations can result in systemic inflammation. Long sleep duration $(>8 \mathrm{~h})$ are associated with subclinical inflammation and increased arterial stiffness $[19,20]$, while sleep curtailment increases proinflammatory cytokine [21], highsensitivity C-reactive protein [22], and white blood cell [23] levels, which causes endothelial dysfunction and promotes the incidence of vascular complications of diabetes [24]. Third, changes in the sympathetic nervous system by long or short sleep durations may cause high levels of catecholamines and increase blood pressure and heart rate [25]. Sleep regulates the activity of the hypothalamic pituitary adrenal (HPA) axis, which was reduced during sleep onset and the early stages of sleep, and was activated during the later stages of sleep [26, 27]. Therefore, short sleep durations may weaken the inhibitory effect of early-stage sleep on the HPA axis. Conversely, long sleep durations may enhance the activation effect of rapid eye movement stage on the HPA axis, thereby maintaining the activity of the HPA axis at a higher level, which has adverse effects on metabolic health [27].

\section{Study strengths and limitations}

The strengths of the present study is its cohort design and the relatively large number of participants, which enabled us to investigate the causal relationship of sleep duration and the health outcomes. In addition, information on a wide range of potential confounders/modifiers and their potential effects were taken into account. The present study also has several limitations to acknowledge. First, the study was limited by retrospective nature. Second, objective information on obstructive sleep

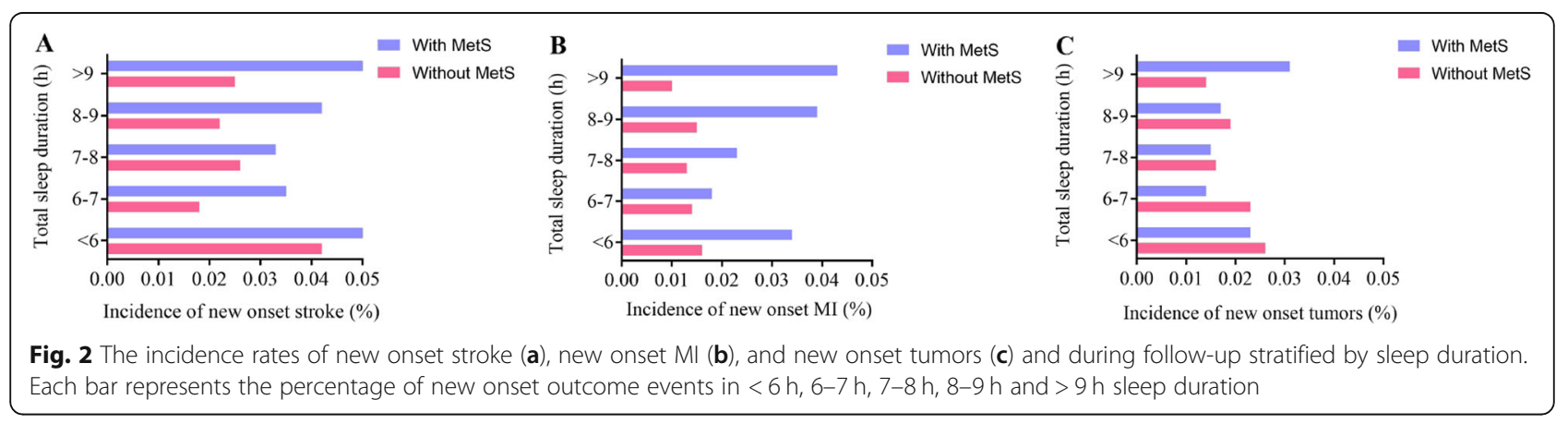




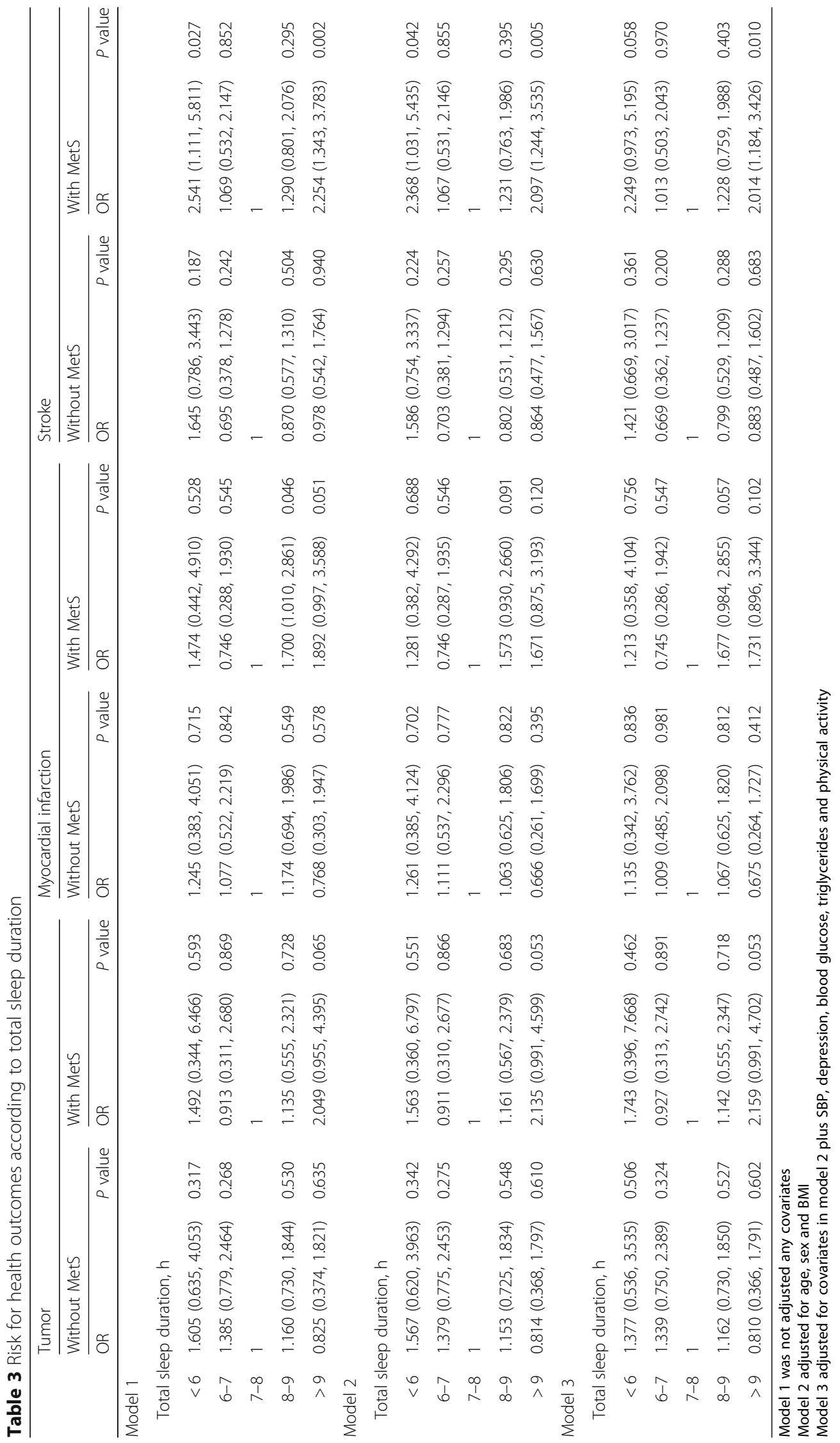


apnea (OSA), a cardiovascular risk factor [28], was not available and thus not considered in this study. However, the use of objective methods (like polysomnography) to accurately measure the OSA is usually not feasible in large studies of general populations, which is a common limitation of sleep-related epidemiological studies [9]. Third, the sample size might fail to reach statistical power for some outcomes (MI and tumors) and unable to well represent Chinese population, so the results should be cautiously generalized. Forth, sleep duration was determined according to a self-reported questionnaire, this parameter was not measured objectively although similar to many prior epidemiological studies.

\section{Conclusions}

The results showed that long sleep duration $(>9 \mathrm{~h})$ significantly increased the risk of stroke but not MI and tumors in individuals with MetS compared with 7-8 h of sleep duration. Short sleep duration $(<6 \mathrm{~h})$ was not associated with the increased risk of stroke, $\mathrm{MI}$ and tumors in individuals with MetS. These findings revealed the relationships of sleep duration with stroke in a Chinese population with MetS. A near U-shape curve was observed between sleep duration and incident stroke. Future longitudinal studies with large samples are warranted to verify the health effect of sleep duration for patients with Mets.

\section{Supplementary information}

Supplementary information accompanies this paper at https://doi.org/10. 1186/s12944-020-01328-1.

Additional file 1: Fig. S1. Flowchart of participant selection

Additional file 2. CONSORT 2010 Checklist

\section{Abbreviations}

MetS: Metabolic syndrome; CVD: Cardiovascular disease; MI: Myocardial infarction; REACTION: Risk evaluation of cancers in Chinese diabetic individuals; OR: Odds ratio; PHQ-9: Patient health questionnaire-9; BMI: Body mass index; TGs: Triglycerides; TC: Total cholesterol; LDL: Low-density lipoprotein; HDL: High-density lipoprotein; FBG: Fasting blood glucose; PBG: Postprandial blood glucose; HbA1c: Glycosylated hemoglobin A1c; DM: Diabetes mellitus; SBP: Systolic blood pressure; DBP: Diastolic blood pressure; SD: Standard deviation; IQR: Interquartile range; ANOVA: Analysis of variance; Cl: Confidence interval; HPA: Hypothalamic pituitary adrenal; OSA: Obstructive sleep apnea

\section{Acknowledgements}

The authors would like to thank Jia Li, Yingfei Zhu from Nankai University and Haibin Wang from the Medical School of Chinese PLA for the statistical knowledge consultation.

\section{Authors' contributions}

Yiming MU was the project lead for the current study. Yingnan YE, Linxi ZHANG, Anping WANG, and Yuxia Wang collectd the data. Yingnan YE and Shiqing WANG conducted the data analysis. Yingnan YE and Guang NING drafted the manuscript. All the authors revised the manuscript. The author (s) read and approved the final manuscript.

\section{Funding}

The present study was supported by the Chinese Society of Endocrinology, the Key Laboratory for Endocrine and Metabolic Diseases of Ministry of
Health (1994DP131044), the National Key New Drug Creation and Manufacturing Program of Ministry of Science and Technology (2012ZX09303006-001), the National High Technology Research and Development Program of China (863 Program, 2011AA020107), and the National Science and Technology Major Project 288 (2011ZX09307-001-08)

\section{Availability of data and materials}

Additional data are available from the corresponding author for reasonable requesting.

\section{Ethics approval and consent to participate}

All participants were given written informed consent for authorizing researchers to use their information. The study protocol was approved by the Committee on Human Research at Rui-Jin Hospital affiliated with the School of Medicine, Shanghai Jiao Tong University.

Consent for publication

Not applicable.

\section{Competing interests}

The authors declare that they have no conflict of interests.

\section{Author details}

${ }^{1}$ Department of Endocrinology, Chest Hospital Affiliated to Nankai University, School of Medicine, Nankai University, Tianjin 300071, China. ${ }^{2}$ Department of Endocrinology, Chinese PLA General Hospital, Medical School of Chinese PLA, No.28, Fuxing Road, Haidian District, Beijing 100853, China. ${ }^{3}$ Department of Endocrine and Metabolic Diseases, Ruijin Hospital, Shanghai Jiao Tong University School of Medicine, 200025 Shanghai, China.

Received: 29 September 2019 Accepted: 16 June 2020

Published online: 27 June 2020

References

1. Moore K, Shah R. Introduction to the obesity, metabolic syndrome, and CVD compendium. Circ Res. 2020;126:1475-6.

2. Park S, Lee S, Kim Y, Lee Y, Kang MW, Han K, Han SS, Lee H, Lee JP, Joo KW, et al. Altered risk for cardiovascular events with changes in the metabolic syndrome status: a Nationwide population-based study of approximately 10 million persons. Ann Intern Med. 2019;171:875-84.

3. Kim CE, Shin S, Lee HW, Lim J, Lee JK, Shin A, Kang D. Association between sleep duration and metabolic syndrome: a cross-sectional study. BMC Public Health. 2018:18:720.

4. Huang T, Redline S. Cross-sectional and prospective associations of Actigraphy-assessed sleep regularity with metabolic abnormalities: the multi-ethnic study of atherosclerosis. Diabetes Care. 2019;42:1422-9.

5. Xu Q, Song $Y$, Hollenbeck A, Blair A, Schatzkin A, Chen H. Day napping and short night sleeping are associated with higher risk of diabetes in older adults. Diabetes Care. 2010;33:78-83.

6. Patel SR, Hayes AL, Blackwell T, Evans DS, Ancoli-Israel S, Wing YK, Stone KL. The association between sleep patterns and obesity in older adults. Int J Obes. 2014;38:1159-64.

7. Gangwisch JE, Heymsfield SB, Boden-Albala B, Buijs RM, Kreier F, Pickering TG, Rundle AG, Zammit GK, Malaspina D. Short sleep duration as a risk factor for hypertension: analyses of the first National Health and nutrition examination survey. Hypertension. 2006;47:833-9.

8. Lin PMD, Chang KT, Lin YA, Tzeng IS, Chuang HH, Chen JY. Association between self-reported sleep duration and serum lipid profile in a middleaged and elderly population in Taiwan: a community-based, cross-sectional study. BMJ Open. 2017;7:e015964.

9. Wang C, Bangdiwala SI, Rangarajan S, Lear SA, AlHabib KF, Mohan V, Teo K, Poirier P, Tse LA, Liu Z, et al. Association of estimated sleep duration and naps with mortality and cardiovascular events: a study of 116632 people from 21 countries. Eur Heart J. 2019;40:1620-9.

10. Ge B, Guo X. Short and long sleep durations are both associated with increased risk of stroke: a meta-analysis of observational studies. Int J Stroke. 2015:10:177-84

11. García-Perdomo HA, Zapata-Copete J, Rojas-Cerón CA. Sleep duration and risk of all-cause mortality: a systematic review and meta-analysis. Epidemiol Psychiatr Sci. 2019;28:578-88. 
12. Fernandez-Mendoza J, He F, LaGrotte C, Vgontzas AN, Liao D, Bixler EO. Impact of the metabolic syndrome on mortality is modified by objective short sleep duration. J Am Heart Assoc. 2017;6:e005479.

13. Yin J, Jin X, Shan Z, Li S, Huang H, Li P, Peng X, Peng Z, Yu K, Bao W, et al. Relationship of sleep duration with all-cause mortality and cardiovascular events: a systematic review and dose-response meta-analysis of prospective cohort studies. J Am Heart Assoc. 2017;6:e005947.

14. Yaggi HK, Araujo AB, McKinlay JB. Sleep duration as a risk factor for the development of type 2 diabetes. Diabetes Care. 2006;29:657-61.

15. Ning G. Risk evaluation of cAncers in Chinese diabeTic individuals: a IONgitudinal (REACTION) study. J Diabetes. 2012:4:172-3.

16. Wingard DL, Berkman LF. Mortality risk associated with sleeping patterns among adults. Sleep. 1983;6:102-7.

17. Kroenke K, Spitzer RL, Williams JB. The PHQ-9: validity of a brief depression severity measure. J Gen Intern Med. 2001;16:606-13.

18. Chinese Medical Association Metabolic Syndrome Research Collaborative Group. Recommendations on metabolic syndrome from the diabetes Society of Chinese Medical Association. Chin J Diabetes. 2004;12:156-61.

19. Kim CW, Chang Y, Zhao D, Cainzos-Achirica M, Ryu S, Jung HS, Yun KE, Choi Y, Ahn J, Zhang Y, et al. Sleep duration, sleep quality, and markers of subclinical arterial disease in healthy men and women. Arterioscler Thromb Vasc Biol. 2015;35:2238-45.

20. Patel SR, Zhu X, Storfer-Isser A, Mehra R, Jenny NS, Tracy R, Redline S. Sleep duration and biomarkers of inflammation. Sleep. 2009:32:200-4.

21. Vgontzas AN, Zoumakis E, Bixler EO, Lin HM, Follett H, Kales A, Chrousos GP. Adverse effects of modest sleep restriction on sleepiness, performance, and inflammatory cytokines. J Clin Endocrinol Metab. 2004;89:2119-26.

22. Meier-Ewert HK, Ridker PM, Rifai N, Regan MM, Price NJ, Dinges DF, Mullington JM. Effect of sleep loss on C-reactive protein, an inflammatory marker of cardiovascular risk. J Am Coll Cardiol. 2004;43:678-83.

23. Dinges DF, Douglas SD, Zaugg L, Campbell DE, McMann JM, Whitehouse WG, Orne EC, Kapoor SC, Icaza E, Orne MT. Leukocytosis and natural killer cell function parallel neurobehavioral fatigue induced by 64 hours of sleep deprivation. J Clin Invest. 1994;93:1930-9.

24. Yu Y, Lyons TJ. A lethal tetrad in diabetes: hyperglycemia, dyslipidemia, oxidative stress, and endothelial dysfunction. Am J Med Sci. 2005;330:22732.

25. Nagai M, Hoshide S, Kario K. Sleep duration as a risk factor for cardiovascular disease- a review of the recent literature. Curr Cardiol Rev. 2010;6:54-61.

26. Meerlo P, Sgoifo A, Suchecki D. Restricted and disrupted sleep: effects on autonomic function, neuroendocrine stress systems and stress responsivity. Sleep Med Rev. 2008;12:197-210

27. Buckley TM, Schatzberg AF. On the interactions of the hypothalamicpituitary-adrenal (HPA) axis and sleep: normal HPA axis activity and circadian rhythm, exemplary sleep disorders. J Clin Endocrinol Metab. 2005; 90:3106-14.

28. Bikov A, Kolossváry M, Jermendy AL, Drobni ZD, Tarnoki AD, Tarnoki DL, Forgó B, Kovacs DT, Losonczy G, Kunos L, et al. Comprehensive coronary plaque assessment in patients with obstructive sleep apnea. J Sleep Res. 2019;28:e12828

\section{Publisher's Note}

Springer Nature remains neutral with regard to jurisdictional claims in published maps and institutional affiliations.

Ready to submit your research? Choose BMC and benefit from:
- fast, convenient online submission
- thorough peer review by experienced researchers in your field
- rapid publication on acceptance
- support for research data, including large and complex data types
- gold Open Access which fosters wider collaboration and increased citations
- maximum visibility for your research: over 100M website views per year
At BMC, research is always in progress.
Learn more biomedcentral.com/submissions

